\title{
A NEW STRATEGIC WAVE MEASUREMENT STATION OFF NAPLES PORT MAIN BREAKWATER
}

\author{
Luca Centurioni ${ }^{1}$, Lance Braasch ${ }^{1}$, Enrico Di Lauro ${ }^{2}$, Pasquale Contestabile ${ }^{2}$, Francesco De \\ $\mathrm{Leo}^{3}$, Raffaella Casotti ${ }^{4}$, Leopoldo Franco ${ }^{5}$ and Diego Vicinanza ${ }^{2,4}$
}

\begin{abstract}
The accuracy of directional wave spectra sensors is crucial for obtaining accurate forecasts of ocean and coastal wave conditions for scientific and engineering applications. In this paper, a newly designed, low-cost GPS-based wave buoy, called the Directional Wave Spectra Drifter (DWSD), is presented. A field test campaign was conducted at the Gulf of Naples, Italy with the goal of comparing the directional wave properties obtained with the DWSD and with a nearly co-located bottom-mounted Acoustic Doppler Current Profiler (ADCP) from Teledyne RD-Instruments. The comparison shows a very good agreement between the two methodologies. The reliability of this innovative instrument and its low costs allow a large variety of applications, including the implementation of a global, satellitelinked, real-time open-ocean network of drifting directional wave spectra sensors and monitoring the sea-state in harbors to aid ship transit and for planning coastal and offshore constructions. The DWSD is currently in use to better constrain the wave energy climatology with the goal of optimizing the design of a full-scale prototype Wave Energy Converter (WEC) in the port of Naples, Italy.
\end{abstract}

Keywords: GPS drifting buoy (SVP), Directional Wave Spectra Drifter (DWSD), Global Drifter Program (GDP), Moored directional spectra wave buoy, Acoustic Doppler Current Profile (ADCP), Directional Waverider (DWR), surface gravity waves, Wave Energy Converter (WEC).

\section{INTRODUCTION}

Monitoring meteorological and oceanographic conditions is crucial to improve numerical weather prediction models (Centurioni et al., 2016) and to manage and assess the safety of coastal and offshore operations. Wave measurements represent a key feature of environmental monitoring programs in several countries around the world. In-situ wave measurements are important for the calibration and validation of advanced wave models that support coastal warning systems, as well as for the design, construction and operational planning of ports and harbors. Since the early 1960s commercial surfacefollowing wave measuring devices have been deployed to collect in-situ measurements of ocean and coastal surface waves.

In recent years, The Global Positioning System (GPS) technology has been introduced in wave buoys as an alternative to motion package based instruments, which utilize gimballed or strapped down accelerometers along with a compass to measure the pitch, heave and roll of the buoy (Krogstad et al., 1997; Krogstad et al., 1999; Herbers et al., 2012). Modern GPS receivers have improved the performance of GPS-based wave buoys, which have become a robust alternative to traditional wellestablished motion-sensor based sensors such as the Datawell Directional Waverider MKII (DWR-2) and newer generation DWR-3 (De Vries et al., 2003; Jeans et al., 2003; Colbert, 2010; Herbers et al., 2012). The GPS technology is also used to obtain the geo-location of Lagrangian Surface Velocity program (SVP) drifters used to measure the world ocean surface circulation (Niiler, 2001; Maximenko et al., 2013, Centurioni, 2016) and for other heavily instrumented drifting buoys designed for nearshore or surf-zone applications (e.g. Postacchini et al., 2016).

The GPS measurement principle is based on the Doppler shift of the satellite signal frequency and provides the three velocity components of the buoy and thus of the sea surface, under the assumption that the buoy is a good water surface follower. The advantages of this technology are both practical and economical (Krogstad et al., 1999). The GPS receiver is very cost-effective and can be implemented in small, light-weight buoys, which can be deployed from small boats. The contained dimensions of Directional Wave Spectra Drifter (DWSD hereafter) described in this paper result in a better response

\footnotetext{
${ }^{1}$ Scripps Institution of Oceanography, Climate, Atmospheric Sciences, and Physical Oceanography, University California San Diego, La Jolla, CA 92093 USA

${ }^{2}$ Department of Civil Engineering, Design, Building, and Environment, University of Campania "Luigi Vanvitelli", Caserta 81100, Italy

${ }^{3}$ Dipartimento di Ingegneria Civile, Chimica e Ambientale, University of Genova, Via Montallegro 1, 16145 Genova, Italy

${ }^{4}$ Stazione Zoologica Anton Dohrn di Napoli, Villa Comunale, Naples 180121, Italy

5 Department of Civil Engineering, Università di Roma Tre, via V.Volterra 62, 00146 Rome, Italy
} 
of the buoy to high wave frequency, thus extending the observation range. Furthermore, since there are no moving parts, fluxgate compasses and the velocity of the water surface is measured in a fixed reference frame from external GPS signals, the DWSD does not need calibration. If the DSWD is deployed as a fixed installation, particular care is needed in the design of the mooring line or the buoy and the GPS antenna will submerge, thus stopping the velocity data acquisition and introducing gaps in the velocity time series. The submerging force can be reduced by reducing the mooring line angle with conventional mooring design solutions utilizing a secondary float or natural rubber bungee. A possible alternative to a vertical mooring could be a horizontal mooring to a vessel or float. Such a configuration mitigates the problem of the buoy submersion while preventing the buoy from getting adrift (de Vries, 2007). Other potential disadvantages of this innovative system are the possible errors and biases of the GPS measurements, classified as satellite-dependent errors, signal propagation-dependent errors and receiver-dependent errors (Joodaki et al., 2013).

In this work, a GPS-based DWSD, recently developed by the Lagrangian Drifter Laboratory (LDL) at Scripps Institution of Oceanography (SIO), is evaluated. In the next two sections we describe the technical characteristics of the device and the data processing methodology, followed by the details of the test campaign, that was designed to compare the performance of the DWSD deployed in the proximity of a bottom-mounted Teledyne-RD Instruments Acoustic Doppler Current Profiler (ADCP) in the Gulf of Naples, Italy. The results, conclusions and future applications are discussed in the last two sections.

\section{THE DWSD}

Stemming from the drifter design adopted by the Global Drifter Program (GDP) (Niiler, 2001; Maximenko et al., 2013, Centurioni et al. 2016), the DWSD (Fig. 1), consists of a sphere with a diameter of $0.39 \mathrm{~m}, 12 \mathrm{Kg}$ weight and replaceable alkaline or lithium batteries.

The DWSD GPS sensor measures the vertical (w), zonal (east-west, $\mathrm{u}$ ) and meridional (south-north, v) velocity components of the buoy. Times series of $u(t), v(t)$ and $w(t)$ are sampled for $\approx 17 \mathrm{~min}$ at $2 \mathrm{~Hz}$ and are split into 4 overlapping segments of $256 \mathrm{~s}$ that are subsequently averaged. The power spectral density, co-spectra and quadrature-spectra parameters are derived with the Fourier transforms of the correlation functions of each pair of the velocity time-series, giving the First-5 independent Fourier coefficients $\left(a_{0}, a_{1}, a_{2}, b_{1}, b_{2}\right)$ and thus the wave spectra for each hourly (and optionally, half-hourly) sea state. For each measured sea state, the three velocity components, the computed first 5 Fourier coefficients and the directional wave parameters can be stored onboard into an optional data logger while platform information (timestamp latitude, longitude, battery voltage, internal pressure, temperature and humidity) at start of data collection, directional wave parameters and optionally, the first 5 Fourier coefficients from $0.031 \mathrm{~Hz}-0.496 \mathrm{~Hz}$ with $1 / 256 \mathrm{~Hz}$ bandwidth are transmitted to shore in real-time through the Iridium satellite system. Using two-way Iridium communication, the GPS-based wave buoy can be programmed while deployed to modify the duration of sampling in multiples of 256 seconds, deployment depth, as well as toggle first 5 reporting to shore for power consumption and telemetry cost savings. All of the transmitted wave data, as well as platform status are accessible in real time on a dedicated website.

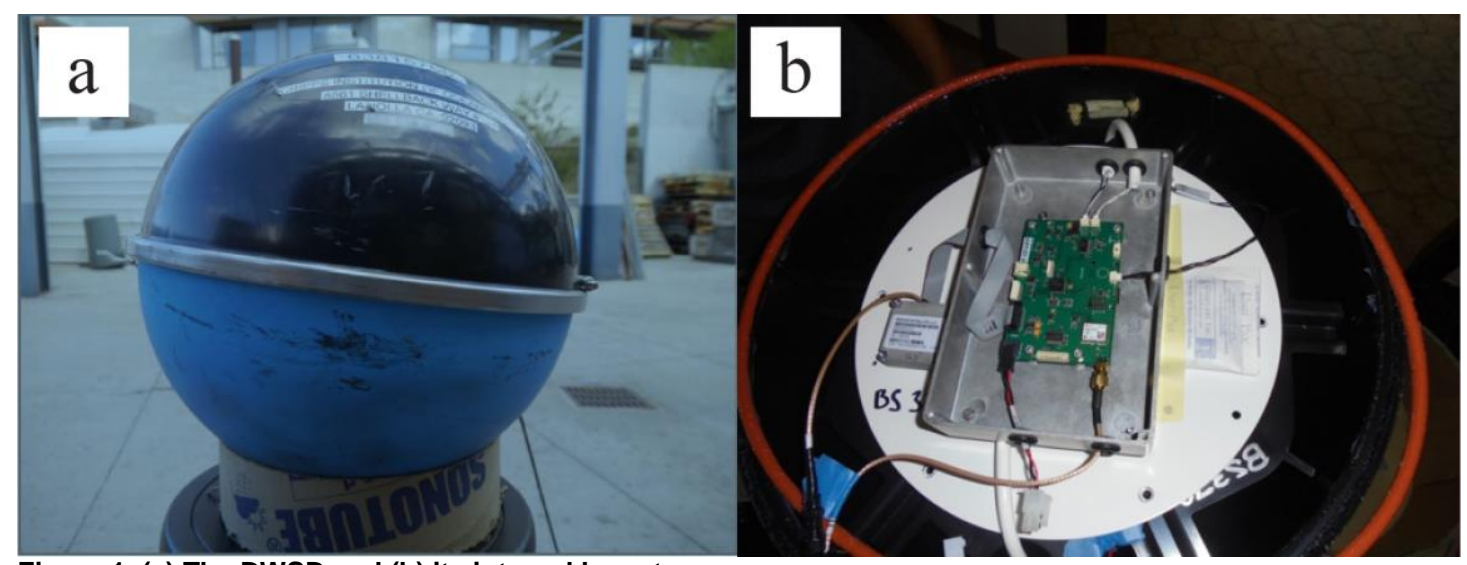

Figure 1. (a) The DWSD and (b) its internal layout. 


\section{DATA PROCESSING}

\section{Directional and non-directional wave spectra}

The directional variance spectra $S(f, \theta)$ of each sea state measured by the DWSD is estimated using the truncated Fourier series up to the second-order terms, expressed as (Lounguet-Higgins et al., 1963; Mitsuyasu et al., 1975; Long, 1980):

$$
S(f, \theta)=\frac{a_{0}}{2 \pi}\left\{1+2 \sum_{m=1}^{2}\left[a_{m} \cos (m \theta)+b_{m} \sin (m \theta)\right]\right\}
$$

The first five coefficients $\left(a_{0}, a_{1}, a_{2}, b_{1}, b_{2}\right)$ of the truncated Fourier series in Eq. 1 are obtained from the complex cross-spectral and quadrature spectra $\mathrm{C}_{11}, \mathrm{C}_{22}, \mathrm{C}_{33}, \mathrm{C}_{23}, \mathrm{Q}_{12}, \mathrm{Q}_{13}$ using the relations for single-point measuring devices recording the three velocities components (Benoit et al., 1997):

$$
\begin{gathered}
a_{0}(f)=C_{11}\left(\frac{1}{2 \pi f} \frac{\sinh (k d)}{\sinh (k(d+z))}\right)^{2} \\
a_{1}(f)=\frac{Q_{12}}{\sqrt{C_{11}\left(C_{22}+C_{33}\right)}} \\
b_{1}(f)=\frac{Q_{13}}{\sqrt{C_{11}\left(C_{22}+C_{33}\right)}} \\
a_{2}(f)=\frac{C_{22}-C_{33}}{C_{22}+C_{33}} \\
b_{2}(f)=\frac{2 \cdot C_{23}}{C_{22}+C_{33}}
\end{gathered}
$$

The wavenumber $k$, defined as $2 \pi / \lambda$, where $\lambda$ is the wavelength of the harmonic wave, is related to the frequency $f$ by the dispersion relation of the linear wave theory:

$$
(2 \pi f)^{2}=(g k) \tanh (k d)
$$

In Eq. 7, $g$ is the acceleration due to gravity and $d$ is the water depth.

The shallow water correction applied in the DWSD onboard processing software is then (Herbers et al, 2012):

$$
C_{11}=\tanh ^{2}(k d)\left[C_{22}+C_{33}\right]
$$

\section{Wave Parameters}

The directional wave spectra $S(f, \theta)$ in Eq. 1 can be also be written as (Huang et al., 1998):

$$
S(f, \theta)=E(f) \cdot D(f, \theta)
$$

In Eq. 9, $E(f)$ is the non-directional variance spectrum estimated from the sea-surface elevation,

$$
E(f)=\int_{0}^{2 \pi} S(f, \theta) d \theta=C_{11}(f)
$$

and $D(f, \theta)$ is the Directional Spreading Function (DSF), which represents the directional distribution of the variance at each frequency. In this paper, $D(f, \theta)$ is computed as (Steele et al., 1992):

$$
D(f, \theta)=\frac{1}{\pi}\left(\frac{1}{2}+r_{1} \cos \left[\theta-\theta_{1}\right]+r_{1} \cos \left[2\left(\theta-\theta_{2}\right)\right]\right)
$$

where:

$$
\begin{aligned}
& r_{1}=\frac{1}{a_{0}}\left(a_{1}{ }^{2}+b_{1}{ }^{2}\right)^{0.5} \\
& r_{2}=\frac{1}{a_{0}}\left(a_{2}{ }^{2}+b_{2}{ }^{2}\right)^{0.5}
\end{aligned}
$$




$$
\begin{aligned}
& \theta_{1}=\tan ^{-1}\left(\frac{b_{1}}{a_{1}}\right) \\
& \theta_{2}=\frac{1}{2} \tan ^{-1}\left(\frac{b_{2}}{a_{2}}\right)
\end{aligned}
$$

$\theta_{1}$ and $\theta_{2}$ are called, respectively, the mean wave direction and principal wave direction. The two solutions of Eq. 15 for $\theta_{2}$ differ by $\pi$, and the value closer to $\theta_{1}$ is used in this work. Both $\theta_{1}$ and $\theta_{2}$ do not depend on the vertical GPS velocity, which may be noisier than the horizontal velocity (Colbert, 2010). The wave parameters are calculated from the directional and non-directional wave spectra. The significant wave height, $H_{s}$, is obtained from the wave elevation variance $\mathrm{m}_{0}$ :

$$
H_{s}=4.004 \sqrt{m_{0}}
$$

where $m_{0}$ is the zeroth-order moment of the non-directional wave spectrum $E(f)$, defined by:

$$
m_{0}=\pi \Delta f \sum_{n=1}^{N_{b}} a_{0, n} \quad n=1,2, \ldots, N_{b}
$$

where $\Delta \mathrm{f}=0.0039 \mathrm{~Hz}$ is the frequency bandwidth of the DWSD and $N_{b}$ is the number of bands in the frequency range $0.039 \mathrm{~Hz}<\mathrm{f}<0.49 \mathrm{~Hz}$.

The mean wave period is defined as:

$$
T_{a}=\frac{m_{0}}{m_{1}}
$$

where $m_{l}$ is the first-order moment defined as:

$$
m_{1}=\pi \Delta f \sum_{n=1}^{N_{n}} f_{n} \cdot a_{0, n}
$$

The peak period, $T_{p}$, is defined by the reciprocal of the center frequency of the non-directional spectral band with the maximum spectral density, $f_{p}$ :

$$
T_{p}=\frac{1}{f_{p}}
$$

Finally, the wave peak direction, $D_{p}$, is defined as the wave direction (Eq. 14) at the maximum of directional wave spectra $S(f, \theta)$ :

$$
D_{p}=\theta_{1}\left(f_{p}\right)=\tan ^{-1}\left(\frac{b_{1}}{a_{1}}\right)_{f=f_{p}}
$$

In this work, the peak direction is converted according to the nautical convention, i.e. as the incoming wave direction, measured clockwise from the north and time is expressed in Coordinated Universal Time (UTC). The comparison of the wave parameters is performed for wind waves only since they contained the largest energy (Earle, 1984; Voorrips et al., 1997; Wang and Hwang, 2001; Gilhousen and Hervey, 2001; Violante-Carvalho et al., 2002; Portilla et al., 2009; Portilla et al., 2015), using a separation frequency $\mathrm{f}_{\mathrm{s}}=0.11 \mathrm{~Hz}$. Fig. 2 shows an example the non-directional variance spectrum $E(f)$ with the separation frequency marked between two distinct peaks. In other words, in the following, we restrict the analysis to the $0.11 \mathrm{~Hz}-0.49 \mathrm{~Hz}$ frequency range. 


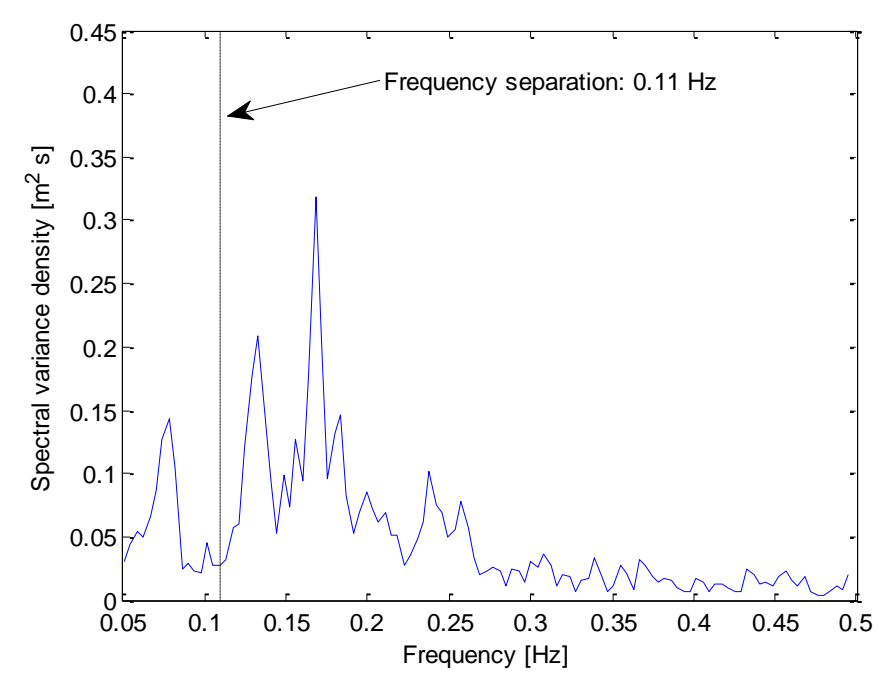

Figure 2. Example of the non-directional spectral variance density $E(f)$ showing the separation frequency $\left(f_{s}\right)$ used to partition the wave spectrum between wind and swell.

\section{EXPERIMENTAL TEST CAMPAIGN}

The DWSD was deployed for approximately 6 days, from May 12 to May 18, 2016 at $40^{\circ} 49.668^{\prime} \mathrm{N}$ and $14^{\circ} 13.984^{\prime} \mathrm{E}$ and was co-located with an ADCP at a water depth of $17.5 \mathrm{~m}$ (Fig. 3) and within 30 $\mathrm{m}$ a distance. The bottom-mounted, upward-looking, four beams, $600 \mathrm{kHz}, \mathrm{ADCP}$ by RDI is part of a wave measurement facility of the Stazione Zoologica "Anton Dohrn", Naples. The ADCP directional wave measurement principle (Pinkel and Smith, 1987; Krogstad et al., 1988; Smith, 1989; Terray et al., 1999; Strong et al., 2000) is based on computing the water velocity from the Doppler shift of the backscattered acoustic pulses along the four inclined beams. The non-directional wave spectra are computed in Earth's coordinates from the water velocity data. The ADCP also measures the nondirectional spectra through echo ranging (surface track) and bottom pressure with a pressure transducer, providing alternative measurements of the surface elevation and of the water depth. It should be noted that the methodology used by the ADCP software to compute the directional wave parameters different from the one used by the DWSD. The ADCP software uses the Maximum Likelihood Method (MLM, e.g. Terray et a., 1999) that computes the spectra from each velocity time series at each sensor, from which the wave phase information is subsequently obtained.

The non-directional wave parameters from the ADCP were computed from both the velocity and surface tracking spectra using a frequency bandwidth of $0.0078 \mathrm{~Hz}$ and using the same separation frequency $\mathrm{f} s=0.11 \mathrm{~Hz}$ use for the DWSD analysis. The deployment configuration settings of the $\mathrm{ADCP}$ are given in Table 1 and the parameters used for processing and extracting the wave parameters are given in Table 2. As a self-consistency check for the ADCP, the wave parameters for which $T_{p}$ computed from the two spectra differed by more than $1 \mathrm{~s}$, were discarded. 


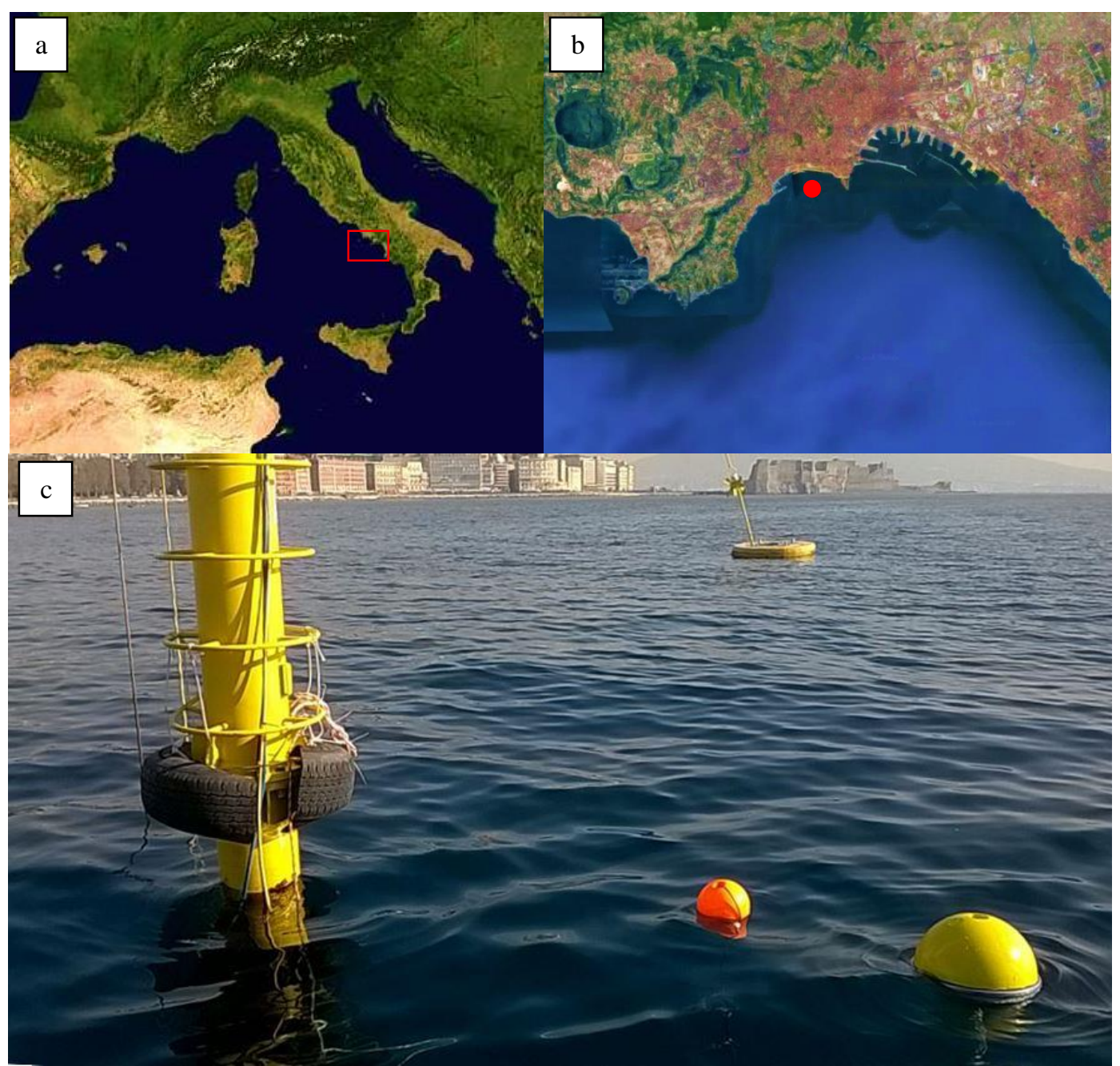

Figure 3. (a) Location of the field site of the test campaign at the Gulf of Naples (Italy) and (b) detail of the test site. (c) the DWSD is the yellow buoy located next to the measurement station where the ADCP was bottom-mounted.

Table 1: Deployment configuration setting of the ADCP

\begin{tabular}{cc}
\hline Water depth & $17.7 \mathrm{~m}$ \\
Sampling interval & $3600 \mathrm{~s}$ \\
ADCP altitude above bottom & $0.5 \mathrm{~m}$ \\
Number of samples per burst (at $2 \mathrm{~Hz})$ & 2100 \\
Size of the depth cell & $0.5 \mathrm{~m}$ \\
Bins used for directional spectrum & $1,13,27,28,29$ \\
Bins used for height spectrum & $1,13,27,28,29$ \\
Maximum cutoff frequency & $0.95 \mathrm{~Hz}$ \\
Minimum Included wave period & $1.05 \mathrm{~s}$ \\
Frequency range & 0 to $1.0 \mathrm{~Hz}$ \\
\hline
\end{tabular}


Table 2: Parameters used for the ADCP wave processing

\begin{tabular}{cc}
\hline Frequency bandwidth & $0.0078 \mathrm{~Hz}$ \\
Maximum upper cutoff frequency & $0.49 \mathrm{~Hz}$ \\
Minimum lower cutoff & $0.11 \mathrm{~Hz}$ \\
Number of direction frequency bands & $128 \mathrm{bands}$ \\
\hline
\end{tabular}

\section{RESULTS}

During the observation period, the sea-state reached peaks of significant wave height of $0.8-0.9 \mathrm{~m}$ on May 14, 2016 (Fig. 4). To quantify the difference of the directional and non-directional wave properties obtained with the two instruments, statistical indicators such as the bias and root mean square error (RMSE) were used:

$$
\begin{gathered}
\text { Bias }=\frac{1}{N} \sum_{i=1}^{N}\left(y_{i}-x_{i}\right) \\
R M S E=\sqrt{\frac{1}{N-1} \sum_{i=1}^{N}\left(y_{i}-x_{i}\right)^{2}}
\end{gathered}
$$

where $y_{i}$ and $x_{i}$ indicate the waves parameters obtained from the two sensors at the $i$-th hourly sea state, and $\mathrm{N}$ is the total number of sea-states under evaluation. The data from which the bias and the RMSE were computed are shown in Fig. 5 results are summarized in Table 3.

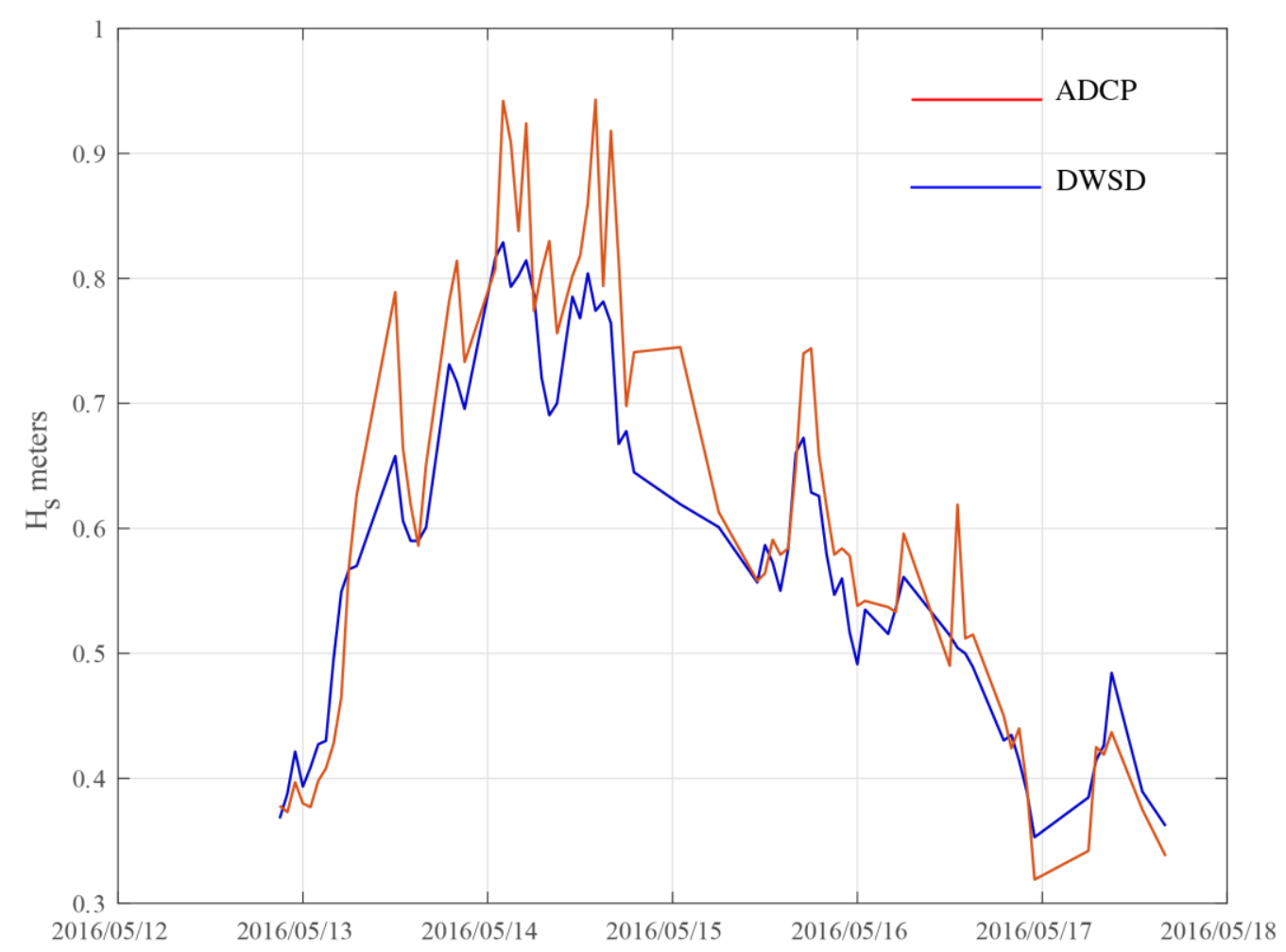

Figure 4. Significant wave height, $\boldsymbol{H}_{s}$, during the observational period. 
Table 3: Comparison on the directional and non-directional wave parameters obtained with the DWSD and the ADCP

\begin{tabular}{lllll} 
& $\mathrm{H}_{\mathrm{s}}(\mathrm{m})$ & $\mathrm{T}_{\mathrm{a}}(\mathrm{s})$ & $\mathrm{T}_{\mathrm{p}}(\mathrm{s})$ & $\mathrm{D}_{\mathrm{p}}\left(^{\circ}\right)$ \\
\hline Bias & 0.03 & -0.02 & 0.3 & 3.7 \\
RSME & 0.05 & 0.2 & 0.7 & 9.9 \\
\hline
\end{tabular}
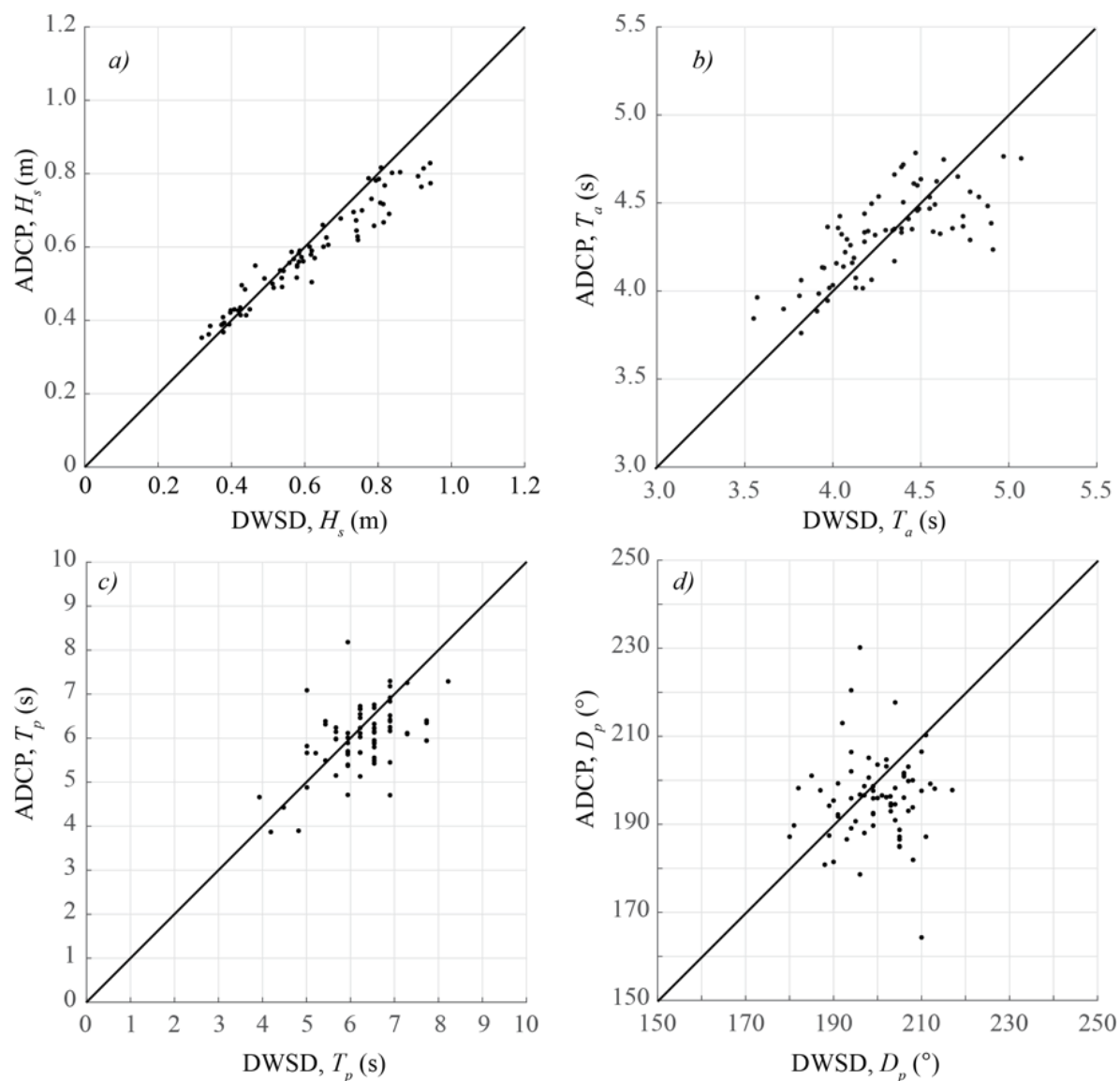

Figure 5. Scatterplots of the directional wave parameters. a) Significant wave height, $H_{s}$ b) Mean wave period, $T_{a}$ c) Peak wave period, $T_{p}$ and d) Peak wave direction, $D_{p}$.

\section{FUTURE PERSPECTIVES AND CONCLUSIONS}

The DWSD has been designed by the LDL of SIO with the objective to implement a global network of drifting wave sensors to provide a real-time data stream of directional wave parameters in support of global and regional wave forecasting, calibration and validation of scatterometer satellites, and ocean physics studies. Despite the short duration of the experiment, the positive comparison between directional and non-directional wave parameters from the DWSD the ADCP indicates that for wind waves the bias and RMSE of the main wave parameters are well within the acceptable range for most coastal engineering applications. Possible reasons of the observed discrepancies include differences in the way the wave parameters are computed and the separation of the two sensors, that, although small, can lead to different wave forms in a very shallow water environment. More comprehensive tests are underway, which include a three-month long comparison of the DWSD performance against an accelerometric directional Datawell waverider deployed at a short distance from each other or mounted directly on its hard-top.

The reliability of the DWSD, its versatility and low costs can support a large number of applications. For instance, it can be considered as a useful tool for the monitoring sea conditions and waterway navigation in harbors and for planning coastal or offshore operations. The instrument could also be 
suitable for meteorological and climatological studies as well as for the calibration and validation of numerical models in coastal areas.

The DWSD can be useful for short-term coastal applications in developing countries, but also for wellestablished long-term semi-offshore (100 m depth) networks, such as the Italian Wave Recording Network (RON) set up in 1989, which is presently out of service for lack of funding. Italy has a remarkable history of coastal wave measurements and the first worldwide wave measuring station was established in the port of Genoa in 1930. A detailed inventory and wave climatology from the RON are described in the Italian Wave Atlas (Franco et al. 2004).

A second DWSD, moored in water depth of $35 \mathrm{~m}, 100 \mathrm{~m}$ offshore of a full-scale prototype Wave Energy Converters (WECs) termed OBREC (Overtopping BReakwater for Energy Conversion, Fig. 6) (Vicinanza et al, 2013; Vicinanza et al, 2014; Contestabile et al., 2015; Contestabile et al., 2016; Contestabile et al., 2017a; Contestabile et al., 2017b; Contestabile et al., 2017c), is under evaluation.
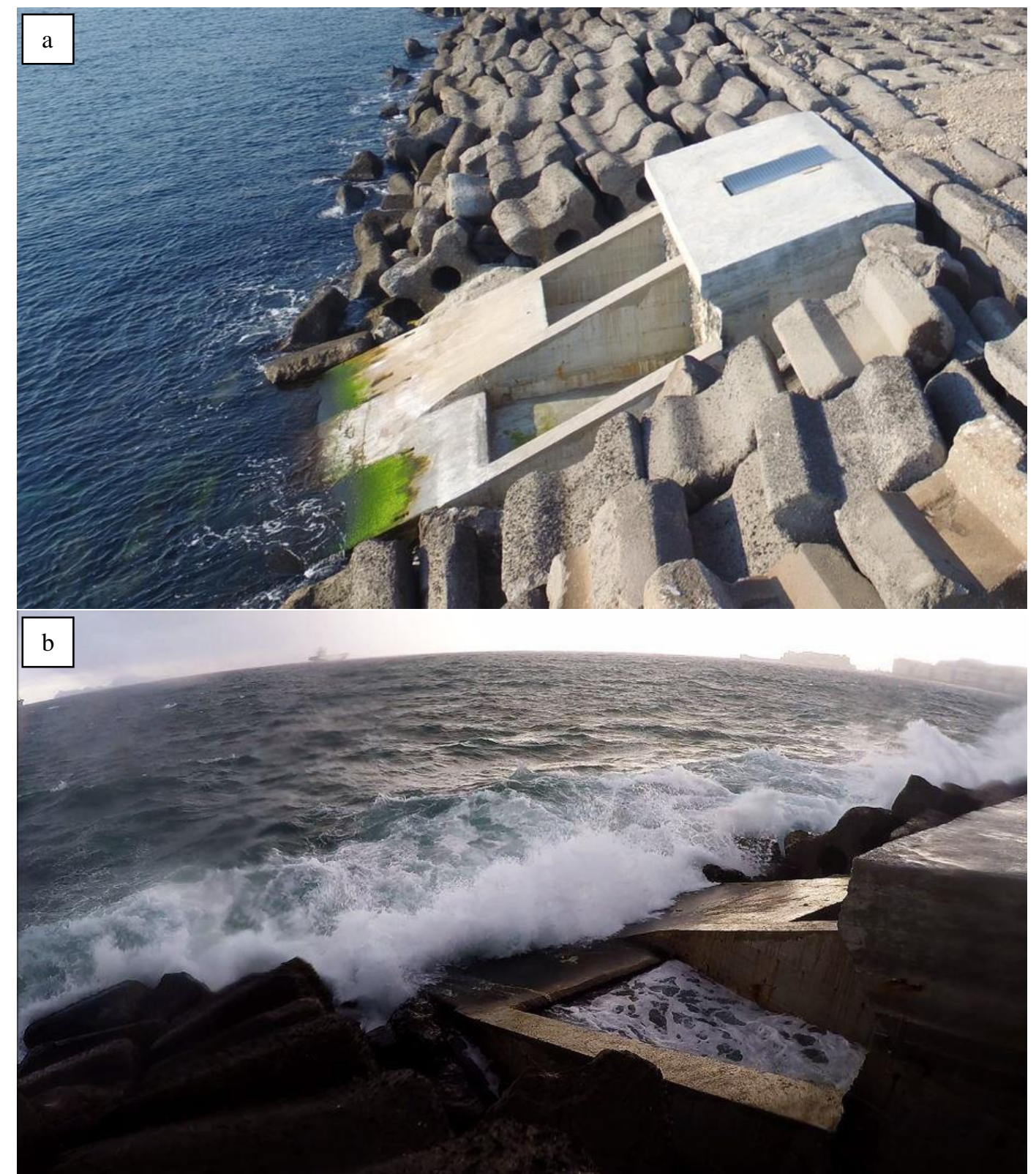

Figure 6. OBREC prototype after his construction (a) and during a wave storm in January 2016 with filled reservoirs (b)

The OBREC is designed to harvest the energy of the overtopping of the incoming waves to generate electrical power and represents the world's first prototype of an "hybrid" WEC and can be integrated 
into an existing coastal defense structure. The OBREC, whose geometry stems from recent works on the Sea Slot-cone Generator (SSG) wave energy converter (Buccino et al., 2015a; Buccino et al., 2015b), features a frontal planar ramp to facilitate the filling of a reservoir with a water level higher than the still sea level. The potential energy of the water in the reservoir is then converted into electric power with low-head turbines coupled with electrical generators located in a machine room situated beside the reservoir. The full-scale prototype is instrumented to measure its overall structural, hydraulic, power generation performance and environmental risks (Azzellino et al., 2013).

The wave observations from the two DSWD currently installed in the Gulf of Naples will be also used to validate the wave forecasting of the area as well as to calibrate and validate the numerical models for a more accurate assessment of the climatological wave energy available at the OBREC site.

\section{ACKNOWLEDGMENTS}

The development of the DWSD is supported by the NOAA grant \# NA10OAR4320156 "The Global Drifter Program".

This work was also supported by the Italian Ministry of Education, University and Research (MIUR) trough the following projects:

- National Operational Programme for "Research and Competitiveness" 2007-2013 (NOP for $\mathrm{R} \& \mathrm{C}$ ) founded project PON04a3_00303 titled “DIMEMO-DIga Marittima per l'Energia del Moto Ondoso" (Maritime Breakwater for Wave Energy Conversion), Project PON04a3_00303.

- EMSO-MedIT Strengthening of multidisciplinary marine research infrastructure in Sicily, Campania and Puglia, ESFRI EMSO, project PAC01_00044.

Partiall support for LC was also provided by the University of Campania "Luigi Vanvitelli" trough the Visiting Professors scholarship 2016.

\section{REFERENCES}

Azzellino, A., D. Conley, D. Vicinanza, and J. Kofoed. 2013. Marine Renewable Energies: Perspectives and Implications for Marine Ecosystems, Scientific World Journal, vol. 2013, 547563.

Benoit, M., P. Frigaard, and H.A. Schäffer. 1997. Analysing multidirectional wave spectra: a tentative classification of available methods, In Proceedings of the 1997 IAHR conference, San Francisco, $131-158$

Buccino, M., D. Vicinanza, D. Salerno, D. Banfi, and M. Calabrese. 2015a. Nature and magnitude of wave loadings at Seawave Slot-cone Generators, Ocean Engineering, 95, 34-58.

Buccino, M., D. Stagonas, and D. Vicinanza. 2015b. Development of a composite sea wall wave energy converter system, Renewable Energy, 81, 509-522.

Centurioni, L., A. Horányi, C. Cardinali, E. Charpentier and R. Lumpkin. 2016. A Global Ocean Observing System for Measuring Sea Level Atmospheric Pressure: Effects and Impacts on Numerical Weather Prediction. Bulletin of the American Meteorological Society, (In press)

Colbert D. 2010. Field Evaluation of Ocean Wave Measurements with GPS Buoy, PhD dissertation, Monterey, California. Naval Postgraduate School.

Contestabile, P., V. Ferrante, and D. Vicinanza. 2015. Wave Energy Resource along the Coast of Santa Catarina (Brazil), Energies 8(12), 14219-14243.

Contestabile, P., V. Ferrante, E. Di Lauro, and D. Vicinanza. 2016. Prototype overtopping breakwater for wave energy conversion at port of Naples, Proceeding of the $26^{\text {th }}$ International Ocean and Polar Engineering Conference, ISOPE, 616-621.

Contestabile, P., C. Iuppa, E. Di Lauro, L. Cavallaro, T. Lykke Andersen, and D. Vicinanza, 2017a. Wave loadings acting on innovative rubble mound breakwater for overtopping wave energy conversion, Coastal Engineering, 122, 60-74.

Contestabile, P., E. Di Lauro, M. Buccino, and D. Vicinanza. 2017b. Economic assessment of Overtopping BReakwater for Energy Conversion (OBREC): a case study in Western Australia, Sustainability, 9(1), 51.

Contestabile, P., V. Ferrante, E. Di Lauro, and D. Vicinanza. 2017c. Full-scale prototype of an overtopping breakwater for wave energy conversion, Proceeding of the $35^{\text {th }}$ International Conference Coastal Engineering, ICCE, Antalya, Turkey.

de Vries, J.J. 2007. Designing a GPS-based mini wave buoy, International Ocean Systems, May/June 2007, 11(3), 20-23. 
de Vries, J.J., J. Waldron, and V. Cunningham. 2003. Field tests of the new datawell DWR-G GPS wave buoy, Sea Technology, 44(12), 50-55.

Earle, M. D. 1984. Development of algorithms for separation of sea and swell, National Data Buoy Center Tech Rep MEC-87-1, Hancock County, 53, 585.

Franco, L., R. Piscopia, S. Corsini, and R. Inghilesi. 2004. L'Atlante delle onde nei mari italiani Italian Wave Atlas, Full Final Report by APAT-University of Roma Tre, sponsored by AIPCN Italian Section and Italia Navigando, Roma.

Gilhousen, D. B., and R. Hervey. 2001. Improved estimates of swell from moored buoys, In Proc. Fourth International Symposium on Ocean Wave Measurement and Analysis, San Francisco, California, September 2-6, 2001, 387-393.

Herbers, T.H.C., P.F. Jessen, T.T. Janssen, D.B. Colbert, and J.H. MacMahan. 2012. Observing ocean surface waves with GPS-tracked buoys, Journal of Atmospheric and Oceanic Technology, 29(7), 944-959.

Huang M.C., J.Y. Chen. 1998. Wave Direction Analysis from Data Buoys, Ocean Engineering, 25(8), 621-637.

Jeans, G., I. Bellamy, J.J. de Vries, and P. van Weert. 2003. Sea trial of the new Datawell GPS directional Waverider. Proceedings of the IEEE/OES Seventh Working Conference on Current Measurement Technology, IEEE, 145-147.

Joodaki, G., H. Nahavandchi, and K. Cheng. 2013. Ocean wave measurement using GPS buoys, Journal of Geodetic Science, 3(3), 163-172.

Krogstad, H.E., R.L. Gordon, and M.C. Miller. 1988. High resolution directional wave spectra from horizontally mounted acoustic Doppler current meters, Journal of Atmospheric and Oceanic Technology, 5, 340-352.

Krogstad, H.E., S.F. Barstow, O. Haug, P.Ø. Markussen, G. Ueland, and I. Rodriguez. 1997. SMART800: a GPS based directional wave buoy, In Ocean Wave Measurement and Analysis, ASCE, 11821195.

Krogstad, H.E., S.F. Barstow, S.E. Aasen, and I. Rodriguez. 1999. Some recent developments in wave buoy measurement technology, Coastal engineering, 37(3), 309-329.

Long, R.B. 1980. The statistical evaluation of directional spectrum estimates derived from pitch/roll buoy data, Journal of Physical Oceanography, 10, 944-952.

Longuet-Higgins, M.S., D.E. Cartwright, and N.D. Smith. 1963. Observations of the directional spectrum of sea waves using the motions of a floating buoy, Ocean Wave Spectra, Prentice-Hall, Englewood Cliffs, NJ, 111-136.

Maximenko, N., R. Lumpkin, and L. Centurioni. 2013. Ocean surface circulation, In Ocean Circulation and Climate: A 21st Century Perspective, edited by G. Siedler, S.M. Griffies, J. Gould, and J.A. Church, Academic Press, 283-304.

Mitsuyasu, H., F. Tasai, T. Suhara, S. Mizuno, M. Ohkusu, T. Honda, and K. Rikiishi. 1975. Observations of the directional spectrum of ocean waves using a Cloverleaf Buoy, Journal of Physical Oceanography, 5, 750-760.

Niiler, P.P. 2001. The World Ocean Surface Circulation. In Ocean Circulation and Climate, edited by G. Siedler, J. Church and J. Gould. Academic Press, 193-204.

Pinkel, R., and J.A. Smith. 1987. Open ocean surface wave measurements using Doppler sonar, Journal of Geophysical Research, 92, 12,967-12,973.

Portilla, J., L. Cavaleri, and G. Van Vledder. 2015. Wave spectra partitioning and long term statistical distribution, Ocean Modelling, 96, 148-160.

Portilla, J., F.J. Ocampo-Torres, and J. Monbaliu. 2009. Spectral Partitioning and Identification of Wind Sea and Swell, Journal of Atmospheric and Oceanic Technology, 26(1), 107-122.

Postacchini, M., L. R. Centurioni, L. Braasch, M. Brocchini and D. Vicinanza. 2016. Lagrangian Observations of Waves and Currents From the River Drifter, Oceanic Engineering, IEEE Journal of, 41(1), 94-104.

Smith, J.A. 1989. Doppler sonar and surface waves: Range and resolution, Journal of Atmospheric and Oceanic Technology, 6, 680-696.

Steele, K.E., C. Teng, and D.W.C Wang. 1992. Wave direction measurements using pitch-roll buoys, Ocean Engineering, 19 (4), 349-375.

Strong, B., B. Brumley, E.A. Terray, and G.W. Stone, 2000. The performance of ADCP derived wave directional spectra and comparison with other independent measurements. In OCEANS 2000 MTS/IEEE Conference and Exhibition, 1195-1203. 
Terray, E.A., B.H. Brumley, and B. Strong. 1999. Measuring waves and currents with an upwardlooking ADCP, Proceedings IEEE 6th Working Conference on Current Measurement, IEEE Press, 66-71.

Vicinanza, D., J.H. Nørgaard, P. Contestabile, and T. Lykke-Andersen. 2013. Wave loadings acting on overtopping breakwater for energy conversion, Journal of Coastal Research, Special Issue 65, 1669-1674.

Vicinanza D., P. Contestabile, J.H. Nørgaard, T. Lykke-Andersen. 2014. Innovative rubble mound breakwaters for overtopping wave energy conversion, Coastal Engineering, 88, 154170.

Violante-Carvalho, N., C. E. Parente, I. S. Robinson, and L. M. P. Nunes. 2002. On the growth of wind generated waves in a swell dominated region in the South Atlantic, Journal of Offshore Mechanics and Arctic Engineering, ASME, 124, 14-21.

Voorrips, A. C., V. K. Makin, and S. Hasselmann. 1997. Assimilation of wave spectra from pitch-androll buoys in a North Sea wave model, Journal of Geophysics, 102, 5829-5849.

Wang, D. W., and P. A. Hwang. 2001. An operational method for separating wind sea and swell from ocean wave spectra, Journal of Atmospheric and Oceanic Technology, 18, 2052-2062. 